\title{
Correction to: Reason Holism, Individuation, and Embeddedness
}

\author{
Peter Shiu-Hwa Tsu ${ }^{1}$ \\ Published online: 12 November 2018 \\ (C) Springer Nature B.V. 2018
}

\section{Correction to: Ethical Theory and Moral Practice https://doi.org/10.1007/s10677-018-9948-9}

The original version of this article unfortunately contained an error. The acknowledgement of the funding sources was inadvertently omitted by the author.

The funding statement is shown below.

Funding Research on this article is funded by Taiwan's Ministry of Science and Technology [MOST 105-2410H-194 -096 -MY4; MOST 104-2628-H-194 -001 -MY2].

The online version of the original article can be found at https://doi.org/10.1007/s10677-018-9948-9

Peter Shiu-Hwa Tsu u4079238@gmail.com

1 Department of Philosophy, Chung Cheng University, Chia-Yi County, Taiwan 